\title{
Serving the Mental Health Review Tribunal 1966-98
}

\author{
P. Grahame Woolf
}

In a lecture to the Royal College of Psychiatrists, published as an editorial in the British Journal of Psychiatry. Sir John Wood recommended a review of the structure and details of the Mental Health Review Tribunal (MHRT) system (Wood, 1995). The present article is a personal contribution to that review and describes aspects of the MHRT during 30 years of continual change.

The roles of doctors in relation to the MHRT have been reviewed in the Psychiatric Bulletin by Woolf (1991). Despite flurries of lively correspondence during 1994-95, there has been no discussion of the working conditions of medical members.

\section{Inherent problems}

Under the Mental Health Act (1983) access to the tribunal was extended to patients detained for assessment, without anticipating and costing realistically the massive drain upon future resources implied. Now, supervised discharge too carries the right to a tribunal hearing.

Legal aid, free for all applicants, has helped to compensate for the complexity of the statute, with its clumsy 'double negative' formulation which places the burden of proof upon the patient. That extension of legal involvement has, however, brought with it increasing disruption of hospital routine, with frequent presence on the wards of lawyers attending to prepare patients for tribunal hearings, and independent professional experts instructed to assist them.

Patients complain of being 'locked up', but this can be an euphemism for situations of limited control. They sometimes absent themselves from appointments for preliminary medical examinations. By the time of the hearing they may have been discharged, or be on 'extended leave' and perceive the scheduled tribunal as an irrelevancy. They may also have absconded, the tribunal members and clerk none the less required to convene at the hospital, lest they might return for the hearing.

Operational strains have increased with the additional burden of the demands upon everyone to meet the stringent statutory requirements to achieve Section 2 tribunals in extreme haste. The number of those increased beyond expectation, resulting in unacceptable delays in achieving hearings for patients detained under other Sections of the Act. McKenzie \& Waddington (1994) discuss those delays, and review outcomes in Bradford. Oyebode \& Shah (1996) reported a three-fold increase of applications between 1984 and 1993. Outcomes of hearings are generally predictable. Of 356 detained patients studied in 1993-1994, 126 (35\%) appealed but only 52 applications were actually heard, and of those only 18 were discharged.

It is understandable that overstretched hospital and social services staff are sometimes unable and/or unwilling to give the priority which the tribunal expects to the preparation of tribunal reports, and attendance at hearings. Tribunals are increasingly felt to be necessary (by some, unnecessary) evils, which do little to advance the real interests of the applicants, with hearings often stressful, inordinately lengthy and disruptive of normal work (Hambridge, 1995: McLoughlin, 1995). Surprisingly often patients have been discharged from liability to detention shortly before their cases were due to be heard, thereby discharging also the responsible medical officer's obligation to supply a medical report. Putting the whole procedure in place in the context of such vicissitudes is frustrating for everyone, and sometimes felt to be an inappropriate use of valuable professional time for hospital, social service and tribunal personnel alike. The whole costly MHRT exercise is a significant drain upon public service budgets. There is no mechanism to recover costs from defaulting patients or from hospital trusts.

In earlier years MHRTs were relatively infrequent visitors to the hospitals, where they found themselves held in high esteem. Goodwill towards the tribunal has been progressively eroded, especially in the past 10 years, because of the increase of statutory work demanded by legal obligations, including time consuming tasks to satisfy the requirements of managers hearings and the Mental Health Act Commission. All this conflicts with clinical demands, and newer medical contracts under the NHS trusts 
make no allowances for this additional unpaid work. The exigencies of Section 2 hearings lead regularly to the appearance before the tribunal of professionals who do not know the patients, and may have little experience of mental disorder (Wood, 1994). Failure to fulfil the requirements of the tribunal rules is not subject to any real sanction.

Research into the workings of the MHRTs would be facilitated if completion of tribunal reports were required, even when applicants have been discharged and booked hearings cancelled (Woolf, 1988). Systematic individual follow up enquiries are limited logistically by lack of MHRT resources to pursue peripheral and long-term objectives.

\section{Working for the MHRT}

The MHRT operates through peripatetic teams who undertake lengthy journeys to widely scattered health and social service premises, the timing and location of hearings often at the detaining authority's administrative convenience. These are sometimes convened in patently unsatisfactory rooms, unprepared for a judicial hearing, so that tribunal members, who may have travelled considerable distances to arrive early morning, and are rarely afforded the luxury of reserved car parking, may then find themselves assisting with furniture arrangement. These minor frustrations may be perceived as symptomatic of a system in which all is far from right.

Little has been published about the difficulties of the job, which members constantly discuss among themselves. The MHRT has always been under-resourced, and has become relatively more so with the growing volume of work. Perceptions are voiced, not infrequently, that the tribunal is an irrelevant intrusion into the workings of the hospital.

Despite the problems, there are great satisfactions in participating. The requirement for preliminary clinical examinations enables medical members, many of whom are retired from the National Health Service (NHS), to visit hospitals and residential facilities in their regions, gaining thereby valuable insight into the comprehensive changes in hospitals and mental health services over the years. Critical evaluation of tribunal reports, in debate with the responsible medical officer, provides a refresher course in newer approaches to management and treatment, updating knowledge for doctors on both sides of the table. A constructive role for the tribunal, with discussions between the experts in various disciplines present at the hearing, has generally been encouraged by all concerned (Wood, 1995).
During the 1960 s and 1970 s, the outcomes of hearings were not greatly different from those of the present day. Tribunal members would help applicanits to verbalise their case and tested the professional evidence carefully. Hearings were fewer, shorter and more informal in style. Most legal members, and their regional chairmen, were solicitors of wide general experience.

When the MHRT was given the power to discharge restricted patients it was decided, at the insistence of the Home Office, that judges or Queen's Counsels must preside at hearings for section 41 offender patients. Upon their retirement, regional chairmen solicitors tended to be replaced by judges, who brought to the MHRT Crown Court experience and especial concern for restricted patients. The whole process gradually became increasingly complex, and more irksome for all parties involved. Hearings of applications and references in straightforward cases became prolonged inordinately (Hambridge, 1995) to preempt possible criticism. Reasons for decisions now have to be amplified with 'Reasons for Reasons! We were enjoined to word those so as to be 'judicial review-proof'.

Because tribunal office clerks are under intense pressure to confirm arrangements as quickly as possible, availability for prompt response at the end of a phone has become a premium consideration, and members may have to rearrange their commitments at very short notice. After having done so, late discharges, sometimes inexplicable, may occur (Woolf, 1988). These, and cancellations of hearings for other reasons, carry no contingency provision for cancellation fees.

Professional members have no regular opportunities to meet with their peers to advise about working conditions. The need for new medical members to replace those retiring has outstripped supply in recent years (Gunn, 1995) and recruitment has been limited because of the unsatisfactory remuneration structure and other aspects of the work, which tend to preclude active membership for NHS consultants in fulltime posts. The consequence has been ever increasing demands placed upon ageing doctors.

\section{Terms and conditions of service}

Medical members of the MHRT, all of them experienced senior consultant psychiatrists, have no real voice in the organisation and no representation in reviewing the terms and conditions of service. Medical membership is normally renewed on a three year basis, subject to secret, confidential recommendation, or veto, by the regional chairman and tribunal clerk. There is no security whatsoever. The standard letters of appointment and re-appointment sent from the 
Lord Chancellor's Office are chilling in their wording, and have upset many members. Members are advised that their appointments may be terminated at any time without reason stated. Decisions of the Lord Chancellor are not subject to appeal.

Although their task has become increasingly demanding over the years, medical members have never been offered an independent negotiating capability nor any genuine role in decisions taken about their own work. Nor has the MHRT Members' News Sheet, of which I was a co-founder, been able to become seriously embroiled in controversial aspects of working conditions (Howell, 1997). Latterly it has received financial assistance from the Department of Health and its emphasis has increasingly become educational, rather than tackling the 'nitty-gritty' of the job.

\section{Disciplinary powers and democratic accountability}

Regional chairmen are appointed by the Lord Chancellor from among the legal members of the MHRT. Their disparate roles embrace necessarily complex divided loyalties, which have become increasingly difficult to reconcile. In discussion and negotiation with government departments they represent their members. When presiding at hearings, they accept (gracefully, most often) the principle of democratic equality, whereby from time to time their preferred determination of an application may be over-ruled by their medical and lay member colleagues constituting a majority. However, in disciplinary matters, the power and authority of the regional chairman over those same members is perceived as being virtually total, decisions and actions by chairmen being not subject to any recognised form of appeal.

Generally that power has been exercised sensibly and benignly, but individual personal characteristics of power holders within any complex organisation come into play occasionally (Greenblatt, 1986; House, 1991). A lack of checks and balances allows crises to be generated out of resolvable problems.

Explicit extension of the roles of the MHRT chairmen, office and hearing clerks, and of 'others', to include 'monitoring the performance' of medical members, has been felt to be a sinister development, tending inevitably towards undermining the mutual confidence within the tribunal fraternity of earlier years. New emphasis upon disciplinary responsibilities and monitoring' has compromised the former confidence that regional chairmen could be relied upon to support medical members and to represent their interests. Tribunal members are now vulnerable to attacks from outside and within. Lawrence (1995) deals only with monitoring of members by the regional chairmen! He begs the question. 'Who monitors the monitors?' (Quis custodiet ipsus custodiem?)

\section{References}

GREenBlatt, M. (1986) The use and abuse of power in the administration of systems. Psychiatric Annals. 16. $650-652$.

GunN, J. (1995) Mental Health Review Tribunals. Psychiatric Bulletin. 19. 258.

Hambridge, D. (1995) Trial by tribunal. Psychiatric Bulletin. 19. 258.

House. R. J. (1991) The Distribution and Exercise of Power in Complex Organisations. Leadership Quarterly. 2. 23-58.

Howell S. (1997) Editorial. MHRT Members' News Sheet. 18. 1-2.

LAWRENCE, H. H. JUDGE T. (1995) Judging the (tribunal) judges. Tribunals, 2, 9-10.

McKenzie. I. \& WADDington. D. (1994) Mental Health Review Tribunals in Bradford. Psychiatric Bulletin. 18. 55.

McLoughuin. I. (1995) Detention under the Mental Health Act. Psychiatric Bulletin. 19. 514.

OYEBODE, F. \& SHAH, M. (1996) The use of Mental Health Review Tribunals. Psychiatric Bulletin. 20. 653-655.

WoOD. SIR J. (1995) The challenge of individual rights Mental Health Review Tribunals. British Journal of Psychiatry. 166, 417-420.

WooD. P. (1994) Attendance of the RMO at tribunals Psychiatric Bulletin. 18, 375.

Woolf, P. G. (1988) Abortive hearings. MHRT Members News Sheet, 2.8.

- (1991) The role of the doctor in the Mental Health Review Tribunal. Psychiatric Bulletin, 15. 407-409.

P. Grahame Woolf, Consultant Psychiatrist, $2 a$ Vanbrugh Hill. Blackheath. London SE3 7UF. E-mail: peteralexa@yahoo.com 